METALLURGY AND FOUNDRY ENGINEERING - Vol. 35, 2009, No. 2

Andrzej Czarski*

\title{
ASSESSMENT OF A LONG-TERM AND SHORT-TERM PROCESS CAPABILITY IN THE APPROACH OF ANALYSIS OF VARIANCE (ANOVA)
}

\section{INTRODUCTION}

There are plenty of different verified quality tools such as: team work methods (e.g. brainstorming, quality circles), problem solving methods (e.g. flow diagram, decisions diagram, cause-and-effect diagram) and finally statistical techniques [1]. In practical approach statistical methods in quality management are first of all: statistical process control (SPC), measurement system analysis (MSA), statistical acceptance plans and statistical methods in process improvement (ANOVA, DOE etc.) [2-5]. Among the statistical methods mentioned above nowadays the most significant place takes the statistical process control (SPC). One of the fundamental tasks of SPC is the assessment of capability of a process/machine relating to client's expectations. Estimation of a process capability refers to a comparison of the process variability with the expected, tolerable variability defined with the aid of specification limits. The expression of this comparison is a series of different capability indices that are capability indices of first generation (short-term capability $\mathrm{Cp}$, Cpk, long-term capability $\mathrm{Pp}, \mathrm{Ppk})$, capability indices of second generation $(\mathrm{Cpm})$, capability indices in case of non-normal distributions, capability indices for correlated data, capability indices in case of multidimensional analysis etc. $[4,6,7]$.

The study is mainly of a methodological character. There is a deepened interpretation of indices of a long-term and short-term process capability based on a one-way analysis of variance (ANOVA) presented. The performed considerations are illustrated with a computational example based on data concerning heat treatment of drop forgings.

\section{LONG-TERM CAPABILITY, SHORT-TERM CAPABILITY - CONCEPTION, CALCULATION PROCEDURE, INTERPRETATION}

In the long-term and short-term capability approach, analogously to the analysis of variance (ANOVA), the analysis of process variability is being performed considering sources that can be its reasons $[2,3,7]$.

* Ph.D.: Faculty of Metals Engineering and Industrial Computer Sciences, AGH - University of Science and Technology, Kraków, Poland; e-mail: czarski@agh.edu.pl 
The principle of this approach is as follows. The total process variability consists of the variability independent on time that we observe in successive rational subgroups taken from a process and the variability dependent on time observed from a sample to a sample. Relating client's expectations presented as specification limits to the total process variability is expressed in long-term capability indices Pp, Ppk. Relating client's expectations presented as specification limits to a component of the process variability irrespective of time is expressed in short-term capability indices Cp, Cpk [2,3].

Computational formulas to calculate long-term capability indices Pp, Ppk and shortterm capability indices $\mathrm{Cp}, \mathrm{Cpk}$ are shown in Table 1.

Table 1. List of short-term and long-term capability indices - calculation procedure [7]

\begin{tabular}{|c|c|c|}
\hline $\begin{array}{l}\text { PROCESS } \\
\text { VARIABILITY }\end{array}$ & $\begin{array}{l}\text { VARIABILITY INDEPENDENT } \\
\text { ON TIME }\end{array}$ & $\begin{array}{l}\text { TOTAL VARIABILITY } \\
=\text { VARIABILITY INDEPENDENT } \\
\text { ON TIME + VARIABILITY } \\
\text { DEPENDENT ON TIME }\end{array}$ \\
\hline $\begin{array}{l}\text { ASSESSMENT } \\
\text { METHOD }\end{array}$ & subgroups taken from the process & $\begin{array}{l}\text { sample of values created } \\
\text { on the basis of all taken subgroups }\end{array}$ \\
\hline $\begin{array}{l}\text { VARIABILITY } \\
\text { MEASURE }\end{array}$ & $s_{\text {short }}=\sqrt{\overline{s^{2}}}$ & $s_{\text {long }}=\sqrt{\frac{1}{n-1} \sum\left(x_{i}-\bar{x}\right)^{2}}$ \\
\hline \multirow[t]{2}{*}{$\begin{array}{l}\text { CAPABILITY } \\
\text { INDICES }\end{array}$} & $\begin{array}{c}\text { SHORT TERM CAPABILITY* } \\
C_{p}=\frac{U S L-L S L}{6 \cdot s_{\text {short }}} \\
C_{p k}=\min \left(\frac{\bar{x}-L S L}{3 \cdot s_{\text {short }}} ; \frac{U S L-\bar{x}}{3 \cdot s_{\text {short }}}\right)\end{array}$ & $\begin{array}{c}\text { LONG TERM CAPABILITY* } \\
P_{p}=\frac{U S L-L S L}{6 \cdot s_{\text {long }}} \\
P_{p k}=\min \left(\frac{\bar{x}-L S L}{3 \cdot s_{\text {long }}} ; \frac{U S L-\bar{x}}{3 \cdot s_{\text {long }}}\right)\end{array}$ \\
\hline & \multicolumn{2}{|c|}{$\begin{array}{l}\text { *) in case of one-side limit specification (LSL or USL) } \\
\text { only Cpk and Ppk are determined }\end{array}$} \\
\hline \multicolumn{3}{|l|}{ Explanations: } \\
\hline \multicolumn{3}{|r|}{ particular samples } \\
\hline \multicolumn{3}{|c|}{$\begin{array}{l}\text { taken from the process } \\
\text { Note: For the assessment of } \mathrm{s}_{\text {short }} \text { one can use also average range or average standard deviation [7] } \\
\mathrm{s}_{\text {short, }} \mathrm{S}_{\text {long }} \text { standard deviations, adequately the measure of process variability independent } \\
\text { on time and total process variability }\end{array}$} \\
\hline$\overline{\bar{x}}, \bar{x}$ & $\begin{array}{l}\text { es, adequately the average determined on the } \\
\text { e process, and the average determined on th } \\
\text { amples taken (obviously } \bar{x}=\bar{x} \text { ) }\end{array}$ & $\begin{array}{l}\text { basis of averages from particular samples } \\
\text { basis of a range of values created on the }\end{array}$ \\
\hline $\begin{array}{ll}\text { Cp, Cpk } & \text { short-terr } \\
\text { Pp, Ppk } & \text { long-tern } \\
\text { USL, LSL } & \text { upper, lov }\end{array}$ & $\begin{array}{l}\text { apability indices } \\
\text { apability indices } \\
\text { specification limit, respectively }\end{array}$ & \\
\hline
\end{tabular}


The results of assessment of long-term and short-term capability lead to the following conclusions:

- If standard deviations $s_{\text {short }}$ (Tab. 1, eq. I) and $s_{\text {long }}$ (Tab. 1, eq. II) are equal i.e. $s_{\text {short }}=s_{\text {long }}$, the total process variability consists only of variability independent on time.

Equality $s_{\text {short }}=s_{\text {long }}$ involves the equality of adequate short-term and long-term capability indices i.e. $\mathrm{Cp}=\mathrm{Pp}$ and $\mathrm{Cpk}=\mathrm{Ppk}$. (Tab.1, formulae III-VI)

Moreover, if the process is centered that means the average corresponds to a target (a midpoint of the specification area), there are the equalities: $\mathrm{Cpk}=\mathrm{Ppk}$ and $\mathrm{Cp}=\mathrm{Pp}$.

- If there is an inequality $s_{\text {short }}<s_{\text {long }}$, the total process variability is larger than the variability independent on time, so a position of the considered process was being changed significantly in time (e.g. because of periodical changes of raw materials, settings etc.). The inequality $s_{\text {short }}<s_{\text {long }}$ involves the following relations between short-term and long-term capability indices: $\mathrm{Cp}>\mathrm{Pp}$ and $\mathrm{Cpk}>\mathrm{Ppk}$.

- We can demonstrate that there is the following relationship between short-term and long-term process capability indices [3]:

$$
\text { Pp Cpk = Cp Ppk }
$$

The expression (1) can be used for verification of the calculation correctness.

\section{SINGLE FACTOR ANALYSIS OF VARIANCE}

Analysis of variance (ANOVA) is a technique that subdivides the total variation of a set of data into meaningful component parts associated with specific sources of variation for the purpose of testing some hypothesis on the parameters of the model or estimating variance components $[4,8-10]$.

In other words, the aim of ANOVA is to state the existence of impact of a determined factor/factors on the considered parameter. Therefore, it is a technique of analysis of variability sources; from a total variability it is separated a variability caused by a possible influence of analyzed factor/factors. In practice, dependent on quantity of analyzed factors, it is carried out a single factor, two-factor or multifactor analysis of variance (ANOVA) $[8,9]$.

Assumptions of ANOVA are as follows: on each level of analyzed factor/factors the results are normally and independently distributed with the same variance; this assumption can be checked by examining the residuals. The normality assumption can be checked by constructing a normal probability plot. The homogeneity of variance can be checked by the Bartlett or Levene test. The independence assumption can be checked by plotting the residuals against the run order in which the experiment was performed [4, 8-10]

Let's keep the further considerations to a single factor analysis of variance. In case of a model with fixed factor the ANOVA is a test of hypothesis [8, 9]:

Null hypothesis: $\mathrm{H}_{0}\left(\mu_{1}=\mu_{2}=\mu_{\mathrm{i}}=\ldots=\mu_{\mathrm{k}}\right)$ 
Alternative hypothesis: $H_{1}$ (at least two of the $\mu_{i}$ 's are different )

where: $\mu_{1}, \mu_{2}, \mu_{\mathrm{k}}$ - expected values for particular levels of the analyzed factor $(\mathrm{k}-$ number of levels).

In case of a model with random factor of ANOVA i.e. when it is impossible to consider all levels of the analyzed factor the ANOVA is a test of the hypothesis [8,9]:

Null hypothesis: $\mathrm{H}_{0}\left(\sigma^{2}=0\right)$

Alternative hypothesis: $\mathrm{H}_{1}\left(\sigma^{2}>0\right)$

where: $\sigma^{2}$-variance in distribution of levels of the analyzed factor.

The results of the analysis of variance are presented as the ANOVA table (Tab. 2)

Table 2. The ANOVA table

\begin{tabular}{||c|c|c|c||}
\hline $\begin{array}{c}\text { Source of } \\
\text { variation }\end{array}$ & Sum of squares (SS) & Mean square (MS) & $\boldsymbol{F}_{\boldsymbol{o}}$ \\
\hline $\begin{array}{c}\text { Between } \\
\text { factor levels }\end{array}$ & $S S_{\text {Factor }}=n \sum_{i=1}^{k}\left(\bar{x}_{i}-\bar{x}\right)^{2} \quad$ (I) & $M S_{\text {Factor }}=\frac{S S_{F a c t o r}}{k-1}$ (II) & $F_{o}=\frac{M S_{\text {Factor }}}{M S_{E}}$ (III) \\
\hline $\begin{array}{c}\text { Error (within } \\
\text { factor levels) }\end{array}$ & $S S_{E}=\sum_{i=1}^{k} \sum_{j=1}^{n}\left(x_{i j}-\bar{x}_{i}\right)^{2} \quad$ (IV) & $M S_{E}=\frac{S S_{E}}{k(n-1)} \quad$ (V) & \\
\hline $\begin{array}{c}\text { Total } \\
\text { Explanations: }\end{array}$ & $S S_{T}=\sum_{i=1}^{k} \sum_{j=1}^{n}\left(x_{i j}-\bar{x}\right)^{2} \quad$ (VI) & & \\
\hline $\begin{array}{l}x_{i j}-\text { represents the (ij)th observation taken under factor level } i \\
k-\text { number of levels } \\
n-\text { number of observations at each factor level (balanced data) } \\
\bar{x}_{i}-\text { mean value for } i \text {-th level } \\
\bar{x}-\text { overall (grand) mean (parametr common to all factors) }\end{array}$ \\
\hline
\end{tabular}

\section{LONG-TERM AND SHORT-TERM CAPABILITY VERSUS ONE-WAY ANOVA}

From the ANOVA point of view the assessment of a long-term and short-term process capability is as follows:

- the process is analyzed for the sake of a certain parameter significant for quality

- from the process the rational samples are drawn; we assume that the time in which the sample is completed is so short that it does not influence the variability observed within one sample; 
- successive samples drawn from the process are, in the ANOVA meaning, levels of the analyzed factor that is obviously the time;

- because the successive samples represent a subset of a set of all possible levels so we can assume that it is a random model of ANOVA; we verify the hypothesis (5) that the variance in distribution of levels' population assumes the value 0 (in other words we check whether the time impact on the process exists);

- relating to expressions presented in the ANOVA table (Tab. 2):

- sum of squares $\mathrm{SS}_{\mathrm{T}}$ (Tab. 2, formula VI) is a measure of a total variability of the process, on its basis we calculate a standard deviation $s_{\text {long }}$ (compare Tab. 1, formula II):

$$
s_{\text {long }}=\sqrt{S S_{T} /(n-1)}
$$

on the basis of the standard deviation $s_{\text {long }}$, for given specification limits, we calculate long-term capability indices Pp, Ppk (Tab. 2 , formulas V, VI),

- sum of squares $\mathrm{SS}_{\mathrm{E}}$ (Tab. 2, formula IV) and mean square $\mathrm{MS}_{\mathrm{E}}$ (Tab. 2, formula V) are measures of a variability observed in samples i.e. they are measures of variability independent on time, on the basis of $\mathrm{MS}_{\mathrm{E}}$ we calculate a standard deviation $s_{\text {short }}$ (compare Tab. 1, formula I):

$$
s_{\text {short }}=\sqrt{M S_{E}}
$$

on the basis of the standard deviation $s_{\text {long }}$, for given specification limits, we calculate short-term capability indices Cp, Cpk (Tab. 2 , formulas III, IV),

- sum of squares $\mathrm{SS}_{\mathrm{Factor}}\left(\mathrm{Tab} .2\right.$, formula I) and centered sum of squares $\mathrm{MS}_{\mathrm{Factor}}$ (Tab.2, formula II) are measures of a variability caused by time (i.e. a component of the process variability connected with possible changes in the process position in time; in other words they are the measures of variability from a sample to a sample),

- inference about impact significance of a component of variability dependent on time on the process position is carried out on the basis of test statistic value $\mathrm{F}_{0}$ (Tab. 2, formula III); if $\mathrm{F}_{0}>\mathrm{F}_{\alpha, \mathrm{k}-1, \mathrm{k}(\mathrm{n}-1)}(\alpha-$ significance level (risk of making a type I error), $\mathrm{k}-1, \mathrm{k}(\mathrm{n}-1)-$ numbers of degrees of freedom), considering it practically, a time component of variability influences significantly the process position.

\section{EXPERIMENTAL PROCEDURE}

\subsection{Aim, subject of investigations}

The aim of research is an assessment of short-term and long-term capability for the sake of hardness of drop forgings (steel 41Cr4, PN-EN 10083-1+Ap1:2003). The assessment has been performed in "classical" way i.e. using expressions presented in Tab. 1 and in the ANOVA approach. It should be sharply emphasized that starting this analysis the careful 
analysis of the ANOVA assumptions has been made. To verify assumptions concerning residuals normality a graphical normal probability plot has been used, and an equality of variances on tested levels of analyzed factors has been verified using the Bartlett and Levene tests $[8,9]$.

Data for the analysis are shown in Table 3 and Figure 1. The detailed information on the heat treatment and measurements made have been already presented above [7].

Table 3. Results of hardness measurements

\begin{tabular}{|c|c|c|c|c|c|c|c|}
\hline \multirow{2}{*}{$\begin{array}{c}\begin{array}{c}\text { No. of } \\
\text { subgroups }\end{array} \\
1\end{array}$} & \multicolumn{5}{|c|}{ Values } & \multirow{2}{*}{$\begin{array}{c}s^{2} \\
0,70\end{array}$} & \multirow{2}{*}{$\begin{array}{c}\bar{x} \\
34,2\end{array}$} \\
\hline & 34 & 33 & 34 & 35 & 35 & & \\
\hline 2 & 35 & 32 & 34 & 35 & 33 & 1,70 & 33,8 \\
\hline 3 & 33 & 33 & 33 & 33 & 33 & $\mathbf{0 , 0 0}$ & 33,0 \\
\hline 4 & 32 & 34 & 34 & 34 & 34 & $\mathbf{0 , 8 0}$ & 33,6 \\
\hline 5 & 37 & 36 & 37 & 36 & 35 & 0,70 & 36,2 \\
\hline 6 & 36 & 37 & 37 & 37 & 36 & $\mathbf{0 , 3 0}$ & 36,6 \\
\hline 7 & 35 & 38 & 37 & 36 & 37 & 1,30 & 36,6 \\
\hline 8 & 35 & 38 & 35 & 36 & 39 & $\mathbf{3 , 3 0}$ & 36,6 \\
\hline 9 & 36 & 37 & 34 & 36 & 37 & 1,50 & 36,0 \\
\hline 10 & 38 & 38 & 36 & 36 & 36 & 1,20 & 36,8 \\
\hline 11 & 35 & 35 & 36 & 34 & 37 & 1,30 & 35,4 \\
\hline 12 & 36 & 34 & 35 & 35 & 35 & $\mathbf{0 , 5 0}$ & 35,0 \\
\hline 13 & 35 & 35 & 34 & 35 & 36 & $\mathbf{0 , 5 0}$ & 35,0 \\
\hline 14 & 33 & 35 & 33 & 34 & 35 & 1,00 & 34,0 \\
\hline 15 & 35 & 34 & 34 & 34 & 35 & $\mathbf{0 , 3 0}$ & 34,4 \\
\hline 16 & 34 & 33 & 34 & 33 & 34 & $\mathbf{0 , 3 0}$ & 33,6 \\
\hline 17 & 35 & 34 & 33 & 35 & 34 & 0,70 & 34,2 \\
\hline 18 & 35 & 37 & 36 & 37 & 37 & $\mathbf{0 , 8 0}$ & 36,4 \\
\hline 19 & 35 & 35 & 37 & 36 & 36 & 0,70 & 35,8 \\
\hline 20 & 37 & 37 & 36 & 36 & 36 & $\mathbf{0 , 3 0}$ & 36,4 \\
\hline 21 & 35 & 36 & 37 & 36 & 36 & $\mathbf{0 , 5 0}$ & 36,0 \\
\hline 22 & 37 & 34 & 36 & 34 & 35 & 1,70 & 35,2 \\
\hline 23 & 34 & 34 & 34 & 36 & 36 & 1,20 & 34,8 \\
\hline 24 & 34 & 35 & 34 & 34 & 34 & 0,20 & 34,2 \\
\hline 25 & 35 & 33 & 33 & 35 & 35 & 1,20 & 34,2 \\
\hline
\end{tabular}




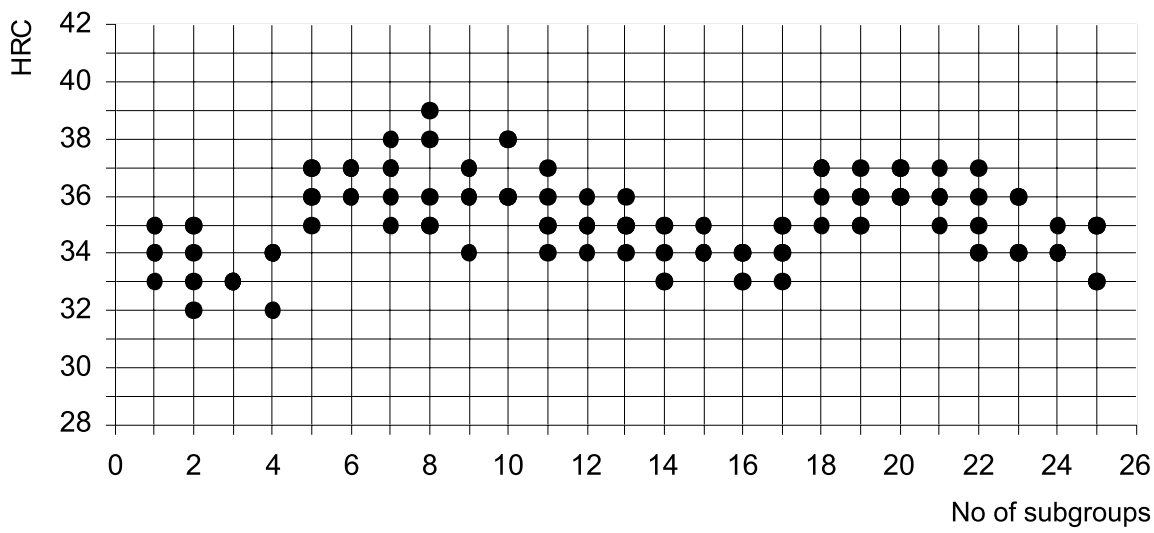

Fig. 1. Results of hardness measurements

According to client's expectations the specification limits for hardness of drop forgings after quenching and tempering are as follows: lower specification limit LSL $=30 \mathrm{HRC}$, upper specification limit USL $=40 \mathrm{HRC}$.

\subsection{Experimental results}

The results of the assessment are presented in Tables 4 and 5 .

Table 4. List of results of process capability assessment (according to Tab. 1)

\begin{tabular}{|c|c|c|c||}
\hline LSL; USL & $30 ; 40$ & Cp & 1,749 \\
\hline$\overline{s^{2}}$ & 0,9080 & $\mathbf{C p k}$ & 1,713 \\
\hline $\mathbf{s}_{\text {short }}$ & 0,9529 & $\mathbf{P p}$ & 1,171 \\
\hline $\mathbf{s}_{\text {long }}$ & 1,4233 & Ppk & 1,143 \\
\hline
\end{tabular}

Table 5. The ANOVA results

\begin{tabular}{||c|c|c|c||}
\hline $\begin{array}{c}\text { Source of } \\
\text { variation }\end{array}$ & Sum of squares (SS) & Mean square (MS) & $\mathbf{F}_{\mathbf{0}}$ \\
\hline $\begin{array}{c}\text { Between } \\
\text { factor levels }\end{array}$ & $\mathrm{SS}_{\mathrm{Factor}}=160,4$ & $\mathrm{MS}_{\mathrm{Factor}}=6,683$ & $\mathrm{~F}_{0}=7,36$ \\
\hline $\begin{array}{c}\text { Error (within } \\
\text { factor levels) }\end{array}$ & $\mathrm{SS}_{\mathrm{E}}=90,8$ & $\mathrm{MS}_{\mathrm{E}}=0,908$ & \\
\hline Total & $\mathrm{SS}_{\mathrm{T}}=251,2$ & & \\
\hline
\end{tabular}


Using the ANOVA results (Tab.5) the following has been determined:

- on the basis of (6); $s_{\text {long }}=1.4233$,

- on the basis of (7); $s_{\text {short }}=0.9529$.

Of course, the achieved values are identical with those ones presented in Table 4, therefore there is no need to determine again the indices Pp, Ppk, Cp, Cpk. Assuming the significance level $\alpha=0.05$, for a number of degrees of freedom $\mathrm{k}-1=24$ ( $\mathrm{k}-$ equals a quantity of samples, Tab. 3) and $\mathrm{k}(\mathrm{n}-1)=100$ ( $\mathrm{n}-\mathrm{a}$ sample size, in the examined case $\mathrm{n}=5$, Tab. 3) from the Fisher's distribution we obtain $\mathrm{F}_{0.05,24,100}=1.627$. Because $\mathrm{F}_{0}>\mathrm{F}_{0.05,24,100}$ (Tab. 5) the process position in time relating to a hardness is a subject to significant changes. This conclusion completes the statistical analysis which should be followed by an interpretation from a technical and technological point of view - but in this study we do not undertake such an interpretation.

\section{SUMMARY}

For the sake of client's expectations it can be acknowledged that the process meets the expectations regarding to the analyzed parameter i.e. a hardness (sufficiently high values of the capability indices $\mathrm{Pp}, \mathrm{Ppk}, \mathrm{Cp}, \mathrm{Cpk}$ ). It is worth noticing that relating to the client's expectations the most significant information are the indices Pp and Ppk, and especially the index Ppk.

From a methodological point of view the assessment of a long-term and short-term process capability is a single factor analysis of variance. Performing such an analysis we ought to remember and verify necessarily the obligatory ANOVA assumptions, particularly relating to a normal distribution and a variance equality.

\section{Acknowledgements}

The financial support from the Polish Ministry of Science and Higher Education, contract AGH no. 10.10.110.797 is gratefully acknowledged.

\section{REFERENCES}

[1] Lock D.: Gower Handbook of Quality Management, Second Edition, PWN, Warsaw, 2002 (in Polish)

[2] Breyfogle F.W.: Implementing Six Sigma. Smarter Solutions Using Statistical Methods, Second Edition, John Wiley\&Sons, Inc., 2003

[3] Joglekar A.M.: Statistical Methods for Six Sigma. In R\&D and Manufacturing, John Wiley\&Sons, Inc., 2003

[4] Montgomery D.C.: Introduction to Statistical Quality Control, Fourth Edition, John Wiley\&Sons, Inc., 2000

[5] Czarski A., Satora K., Matusiewicz P.: Statistical Methods in Quality Management - Process Capability Analysis, Metallurgy and Foundry Engineering, 33 (2007) 121-128

[6] Kotz S., Lovelance C.R.: Process Capability Indices in Theory and Practice, Arnold, 1998 
[7] Czarski A.: Capability Process Assessment in Six Sigma Approach, Metallurgy and Foundry Engineering, 33 (2007) 105-111

[8] Montgomery D.C.: Design and Analysis of Experiments, Six Edition, John Wiley\&Sons, Inc., 2005

[9] Devore J.L.: Probability and Statistics for Engineering and the Sciences, Fifth Edition, Duxbury 2000

[10] Glossary and Tables for Statistical Quality Control, Fourth Edition, ASQ Statistics Division, ASQ Quality Press, 2004

Received

December 2009 